\title{
Screening for Carpal Tunnel Syndrome in Patients on Chronic Hemodialysis
}

\author{
Marin Kuharićl, ${ }^{1,}$ Lada Zibar ${ }^{3}$ \\ ${ }^{1}$ Department of Pathophysiology, Faculty \\ of Medicine, Josip Juraj Strossmayer \\ University of Osijek, ${ }^{2}$ Department of \\ Pathophysiology, Faculty for Dental \\ Medicine and Health Care, Josip Juraj \\ Strossmayer University of Osijek, \\ ${ }^{3}$ Department for Nephrology, Internal \\ Clinic, University Hospital Centre Osijek
}

Correspondence: ladazibar@gmail.com

Tel.: + 385979760917

Fax.: + 38531512201

Received: 29 March 2018

Accepted: 9 March 2019

Key Words: Carpal Tunnel Syndrome Hemodialysis - Amyloidosis - Screening.
Objectives. To determine the prevalence of carpal tunnel syndrome risk in patients on chronic hemodialysis (HD) using Levine questionnaire for assessment of carpal tunnel syndrome - related symptoms severity and patients' functional status and to examine the relation of the determined risk with the participants' demographic, anthropometric and laboratory data. Participants and Methods. This crosssectional study included 78 chronic HD patients at Department for Nephrology in University Hospital Osijek. All participants filled out the Levine questionnaire to examine the severity of carpal tunnel syndrome - related symptoms and their functional state. The participants' demographic, anthropometric and laboratory data were taken from the medical records and statistically analyzed by SPSS for Windows (version 16.0, SPSS Inc., Chicago, IL, SAD). Results. Risk for carpal tunnel syndrome was found in $38.5 \%$ of the participants. No significant differences between patients with and without the risk were found in sex distribution, underlying kidney disease or vascular access. Patients at risk were older $(\mathrm{P}=0.044)$ and had higher body mass index (BMI), (t-test, $\mathrm{P}=0.019)$. Participants' age, $\mathrm{BMI}$ and predialytic serum urea concentration were independent predictors for carpal tunnel syndrome risk $(\mathrm{P}=0.033)$. Conclusion. The prevalence of risk for carpal tunnel syndrome among patients on chronic HD was found in more than one third of patients. Older age, higher BMI and higher predialytic serum urea concentration bear a higher risk. Electromyoneurography is thus often indicated in this population to confirm the diagnosis for consecutive surgical treatment.

\section{Introduction}

Amyloidosis is a term that refers to a group of diseases characterized by extracellular amyloid accumulation in different tissues and organs, which leads to morphological and functional disturbances. Thirty different types of amyloidosis have been discovered, based on the precursor protein that undergoes a pathological change in conformation and is deposited extracellularly. Suspicion of amyloidosis should be based on clinical findings, while a definitive diagnosis is made based on the findings of tissue or organ biopsy $(1,2)$. In hemodialysis-associated amyloidosis, the precursor protein is $\mathrm{A} \beta 2-\mathrm{M}(\beta 2-$ microglobulin), which develops as a complication of end-stage kidney disease and long-term hemodialysis. It is a polypeptide that consists of 99 aminoacids which plays a vital role in the immune system because it is a part of the $\beta$-chain of type $1 \mathrm{MHC}$ (major histocompatibility complex) molecule (3). 
Most of $\beta 2$-microglobulin is normally excreted through the kidneys $(4,5)$. Insufficient filtration and catabolism, continuous production and intradialytic production due to membrane incompatibility all lead to an increase in its serum concentration (6). Normal values of serum $\beta 2$-microglobulin range between 1 and $3 \mu \mathrm{g} / \mathrm{mL}$, while those values can exceed $100 \mu \mathrm{g} / \mathrm{mL}$ in patients with end-stage kidney disease and chronic hemodialysis patients $(7,8)$. The pathogenesis of amyloidosis, time needed to develop and its severity is multifactorial and is connected with the duration of chronic kidney disease, duration of hemodialysis treatment, patient age at the start of hemodialysis treatment, bioincompatibility of hemodialysis membranes and many other clinical features $(9,10)$. Research has shown that deposition of $\mathrm{A} \beta 2-\mathrm{M}$ fibers significantly preceeds the onset of symptoms and clinical findings (10). Disturbances that develop as a consequence of $\mathrm{A} \beta 2-\mathrm{M}$ fiber deposition in the skeletal system are numerous, but the most common one is carpal tunnel syndrome. Hemodialysis-related amyloidosis is one of the most damaging complications of long-term hemodialysis treatment, affecting daily activities and maintenance of quality of life (10).

The most common symptoms of carpal tunnel syndrome are wrist pain, unpleasant tingling, hypoesthesia on the distal end of the median nerve's sensory innervation and a reduction of grip strength. Long-term compression of the median nerve can lead to impaired functionality of the hand as well as hypotrophy, even atrophy of the thenar muscles $(11,12)$. The prevalence of carpal tunnel syndrome caused by hemodialysis-related amyloidosis correlates with the duration of hemodialysis treatment and, according to the literature, it affects $32-50 \%$ patients who have been on hemodialysis for over 10 years. That number jumps to over $80 \%$ in patients who have been on hemodialysis for over 30 years. There are certain factors that contrib- ute to the development of carpal tunnel syndrome in patients on chronic hemodialysis other than $\mathrm{A} \beta 2-\mathrm{M}$ fiber deposits, e.g. venous hypertension distally from the vascular access site, increased volume of the extracellular space, thickening of the transverse carpal ligament, etc. (13-16). A definitive diagnosis is made using electrodiagnostic modalities, which determine the median nerve's quality of motor and sensory impulse generation and transfer $(12,13)$. Treatment of carpal tunnel syndrome can be conservative and surgical. Conservative treatment is recommended for patients with a mild form of the syndrome. For severe cases, surgical decompression of the carpal tunnel is the treatment of choice (13).

Due to the high prevalence of carpal tunnel syndrome among patients on chronic hemodialysis, the aim of this research was to determine the prevalence of carpal tunnel syndrome risk in patients on chronic hemodialysis treated at University Hospital Osijek, using the Levine questionnaire for assessment of carpal tunnel syndrome - related symptoms severity and patients' functional status and to examine the relation of the determined risk with the patients' demographic, anthropometric and laboratory data.

\section{Participants and Methods}

This cross-sectional study was conducted at the Department for Nephrology in University Hospital Osijek with the approval of the Department Head and the Ethical Committee for Research at the Faculty of Medicine of Josip Juraj Strossmayer University of Osijek. Of 89 patients with end-stage renal disease on chronic hemodialysis that were at the Department during the research period, 78 of them accepted to participate and were not in an altered state of consciousness, while 11 patients either rejected to participate or were in an altered state of consciousness. All 
participants were patients on a fixed regime of hemodialysis, three times a week for an average of four hours. All participants filled out the Levine questionnaire to examine the severity of carpal tunnel syndrome - related symptoms (pain, paresthesias, loss of sensation, weakness, nocturnal symptoms) and their functional status (17). The questionnaire consists of two parts. The symptom severity is determined through eleven multiple choice questions which reflect severity - the first choice being the absence of a symptom, while the fifth, final choice being extreme severity. Functional status is determined by adding up participants' answers on a scale from 1 to 5. Participants answer questions about the difficulty of performing eight specific daily activities (writing, buttoning of clothes, holding a book while reading, gripping of a telephone handle, opening of jars, household chores, carrying of grocery bags, bathing and dressing). Answers range from no difficulty to complete inability to perform a certain activity due to hand/wrist symptoms. All the answers are added up and the final result is a number ranging from a minimum of 19 points to a maximum of 95 points (18).

Demographic (age, sex, year of starting hemodialysis, age at start of hemodialysis, duration of hemodialysis, underlying kidney disease, vascular access type), anthropometric (height, weight, BMI) and laboratory (serum concentration of creatinine, urea, hemoglobin, electrolytes before the start of hemodialysis) data were taken from the medical records of the Department for $\mathrm{Ne}$ phrology in University Hospital Osijek.

Analysis of laboratory markers was performed at the Department for Clinical Laboratory Diagnostics in University Hospital Osijek. The reference ranges of markers apply for adults. Serum concentrations of the following markers were analyzed:

- Kidney function markers - serum concentration of creatinine in the reference range for women $(42-80 \mu \mathrm{mol} / \mathrm{L})$ and men $(49-97 \mu \mathrm{mol} / \mathrm{L})$, as well as serum concentration of urea in the reference range for both sexes $(2.8-8.3 \mathrm{mmol} / \mathrm{L})$;

- Hemoglobin in a reference range for women (119-157 g/L) and men (138-175 $\mathrm{g} / \mathrm{L})$;

- Electrolytes - sodium (137-146 mmol/L), potassium (3.9-5.1 $\mathrm{mmol} / \mathrm{L})$, calcium $(2.14-2.53 \mathrm{mmol} / \mathrm{L})$ and phosphorus (0.79-1.42 mmol/L); reference ranges apply to both sexes.

Quality of hemodialysis was determined using Kt/V, which shows elimination of urea which each hemodialysis. Kt/V by hemodialysis is calculated by using predialytic and postdialytic concentration of blood urea using formulas based on the solution to the Gotch-Sargent urea kinetic model for a single hemodialysis. The Jindal formula was used for the purposes of this research:

$$
\frac{K t}{V}=\left(\frac{\text { urea } 1-\text { urea } 2}{\text { urea1 }}\right) \times 4-1.2 \text {, }
$$

where urea 1 is the predialytic serum urea concentration and urea 2 is the postdialytic serum urea concentration (19-22).

\section{Ethics Statement}

The research followed the ethical guidelines and standards set by the Helsinki declaration and the Croatian Health Care Act. The ethics committee of the Faculty of Medicine at the Josip Juraj Strossmayer University of Osijek gave approval to conduct the research.

\section{Statistical Analysis}

Categorical data were descriptively described as absolute and relative frequencies, while numerical data were described as mean and standard deviations, in cases of normal data distribution, while in cases 
showing dispersed data distribution, data were described as medians and interquartile ranges. Tests used for difference between groups with and without risk for carpal tunnel syndrome were chi-square test for nominal variables and t-test (for normally distributed variables) and Mann Whitney $U$ test (for dispersed data distribution) for numeric variables. Correlation was determined using the Spearman coefficient of correlation rho. The ability to predict the risk of carpal tunnel syndrome was determined using the multivariate regression (Hosmer-Lemeshow goodness-of-fit) test. Covariates were chosen as characteristics with $\mathrm{P}<0.100$ in the univariate analysis. All $\mathrm{P}$ values were twosided. Statistical significance was at $\alpha=0.05$. Statistical analysis was performed using SPSS for Windows (version 16.0, SPSS Inc., Chicago, IL, USA) (23).

\section{Results}

Seventy-eight participants on chronic hemodialysis were included in the research, fifty men and twenty-eight women. Median age of participants during the research period was 67 (57-74), while median duration of hemodialysis was 3 years (2-6).

The screening Levine questionnaire determined thirty participants $(38.5 \%)$ had symptoms that classified them as at risk for carpal tunnel syndrome. Table 1 shows the results of the Levine questionnaire among symptomatic participants and the affected hand. Results of the questionnaire were described as overall score, average symptom severity score and average functional state score.

Table 1. Characteristics of Participants at Risk for Carpal Tunnel Syndrome

\begin{tabular}{ll}
\hline Characteristic & Value \\
\hline Affected hand $(\mathrm{N}=30)$ & \\
\hline Right $(\mathrm{N} ; \%)$ & $8(26.7)$ \\
\hline Left $(\mathrm{N} ; \%)$ & $8(26.7)$ \\
\hline Both $(\mathrm{N} ; \%)$ & $14(46.7)$ \\
\hline Levine questionnaire, total score & $31(24-40)^{*}$ \\
\hline Average symptom severity score ${ }^{\dagger}$ & $1.675(1.33-2.49)^{*}$ \\
\hline Average functional status score ${ }^{\dagger}$ & $1.12(1-1.75)^{*}$ \\
\hline
\end{tabular}

${ }^{*}$ Median (interquartile range); ${ }^{\dagger}$ Score ranging from 1 to 5 .

The most common underlying kidney disease which led to end-stage kidney disease was diabetic nephropathy $(\mathrm{N}=21)$, while other common underlying conditions included glomerulonephritides $(\mathrm{N}=20)$, interstitial nephritides $(\mathrm{N}=16)$ and hypertension $(\mathrm{N}=14)$. A statistically significant difference in the distribution of underlying kidney disease among participants with and without carpal tunnel syndrome symptoms was not found (Table 2).

Table 2. Distribution of Underlying Kidney Disease between Participants with and without Risk for Carpal Tunnel Syndrome

\begin{tabular}{llll}
\hline Underlying kidney Disease $(\mathrm{N} ; \%)$ & Participants & & \\
\cline { 2 - 4 } & $\begin{array}{l}\text { All } \\
(\mathrm{N}=78)\end{array}$ & $\begin{array}{l}\text { At risk } \\
(\mathrm{N}=30)\end{array}$ & $\begin{array}{l}\text { Without risk } \\
(\mathrm{N}=48)\end{array}$ \\
\hline Diabetic nephropathy & $21(26.9)$ & $10(33.3)$ & $11(22.9)$ \\
\hline Glomerulonephritis & $20(25.6)$ & $5(16.7)$ & $15(31.3)$ \\
\hline Interstitial nephritis & $16(20.5)$ & $8(26.7)$ & $8(16.7)$ \\
\hline Hypertension & $14(17.9)$ & $5(16.7)$ & $9(18.7)$ \\
\hline Polycystic kidney disease & $4(5.1)$ & 0 & $4(8.3)$ \\
\hline Other & $3(3.8)$ & $2(6.7)$ & $1(2.1)$ \\
\hline
\end{tabular}

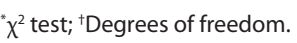


Table 3 ( $3 \mathrm{a}$ and $3 \mathrm{~b}$ ) shows differences in participant characteristics between those with and without symptoms of carpal tunnel syndrome. There were no significant differences in sex distribution between the two groups. There was a larger number of participants who had an arteriovenous fistula as vascular access in the group of participants experiencing symptoms of carpal tunnel syndrome. Participants experiencing symptoms of carpal tunnel syndrome were older (Mann Whitney U test, $\mathrm{P}=0.044$ ) and heavier ( $\mathrm{t}$ test, $\mathrm{P}=0.019$ ) than those who did not experience symptoms. Predialytic serum urea concentration was higher in participants experiencing symptoms of carpal tunnel syndrome, but the difference did not reach statistical significance. There were no statistically significant differences between the two groups in the remaining analyzed characteristics (sex, age at start of hemodialysis treatment, time since starting hemodialysis treatment, vascular access, quality of hemodialysis, predialytic serum concentrations of creatinin, sodium, potassium, calcium and phosophorus).

Table 3a. Differences in Characteristics between Participants with and without Risk for Carpal Tunnel Syndrome

\begin{tabular}{|c|c|c|c|c|c|}
\hline Characteristic & $\begin{array}{l}\text { All participants } \\
(\mathrm{N}=78)\end{array}$ & $\begin{array}{l}\text { Participants at risk } \\
(\mathrm{N}=30)\end{array}$ & $\begin{array}{l}\text { Participants without risk } \\
(\mathrm{N}=48)\end{array}$ & $\begin{array}{l}\text { Test } \\
\text { value }\end{array}$ & $P$ \\
\hline $\operatorname{Sex}[N(\%] ; M: F$ & $\begin{array}{l}50(64.1): \\
28(35.9)\end{array}$ & $\begin{array}{l}18(60): \\
12(40)\end{array}$ & $\begin{array}{l}32 \text { (66.7): } \\
16(33.3)\end{array}$ & $\begin{array}{l}x^{2}=0.36 \\
d f=1^{9}\end{array}$ & $0.550^{*}$ \\
\hline Age in 2016 (year) & $67(57-74)^{\dagger}$ & $70(62-81)^{\dagger}$ & $65(55-73)^{\dagger}$ & $z=-2.01$ & $0.044^{\ddagger}$ \\
\hline Body mass index $\left(\mathrm{kg} / \mathrm{m}^{2}\right)$ & $26.1(4,7)^{\S}$ & $27.6(4,6)^{\S}$ & $25.1(4,5)^{\S}$ & $t=2.4$ & $0.019 \|$ \\
\hline Age at start of hemodialysis (year) & $61.5(53-70)^{\dagger}$ & $61(55-75)^{\dagger}$ & $63,5(52-68)^{\dagger}$ & $z=-1.35$ & $0.177^{\ddagger}$ \\
\hline $\begin{array}{l}\text { Time since starting hemodialysis } \\
\text { (year) }\end{array}$ & $3(2-6)^{\dagger}$ & $4(2-7)^{\dagger}$ & $3(1-5)^{\dagger}$ & $z=-1.27$ & $0.206^{\ddagger}$ \\
\hline $\begin{array}{l}\text { Vascular access [N (\%)], } \\
\text { rteriovenous } \\
\text { fistula:catheter }\end{array}$ & $\begin{array}{l}42(53.8): \\
36(46.2)\end{array}$ & 19 (63.3):11 (36.7) & $23(47.9): 25(52.1)$ & $\begin{array}{l}X^{2}=1.77 \\
d f=1\end{array}$ & $0.184^{*}$ \\
\hline $\begin{array}{l}\text { Vascular access side [N (\%)], } \\
\text { right:left }\end{array}$ & $\begin{array}{l}41(52.5): \\
37(47.5)\end{array}$ & $16(53.3): 14(46.7)$ & $25(52.1): 23(47.9)$ & $\begin{array}{l}x^{2}=0.01 \\
d f=1\end{array}$ & $0.914^{*}$ \\
\hline Hemoglobin (g/l) & $101.6(12.8)^{\S}$ & $102.2(10.3)^{\S}$ & $101.2(14.3)^{\S}$ & $t=0.34$ & $0.735^{\|}$ \\
\hline Creatinine ( $\mu \mathrm{mol} / \mathrm{l})$ & $690.8(192.2)^{\S}$ & $687.4(160.3)^{\S}$ & $692.9(211.3)^{\S}$ & $t=-0.12$ & $0.903^{\|}$ \\
\hline Urea (mmol/l) & $21.57(6.18)^{\S}$ & $23(5.45)^{\S}$ & $20.7(6.45)^{\S}$ & $\mathrm{t}=1.71$ & $0.091^{\|}$ \\
\hline
\end{tabular}

" $\chi^{2}$ test; ${ }^{\dagger}$ Median (Interquartile range); ${ }^{\ddagger}$ Mann-Whitney U test; ${ }^{5} \overline{\mathrm{X}} \pm \mathrm{SD} ;$ "lt-test; ${ }^{\circledR}$ Degrees of freedom.

Table 3b. Differences in Characteristics between Participants with and Without Risk of Carpal Tunnel Syndrome

\begin{tabular}{|c|c|c|c|c|c|}
\hline \multirow[b]{2}{*}{ Characteristic } & \multicolumn{3}{|l|}{ Participants } & \multirow[b]{2}{*}{$t^{*}$} & \multirow[b]{2}{*}{$\mathrm{P}$} \\
\hline & $\begin{array}{l}\text { All } \\
(\mathrm{N}=78) ; \\
\overline{\mathrm{x}} \pm \mathrm{SD}\end{array}$ & $\begin{array}{l}\text { At risk } \\
(\mathrm{N}=30) \\
\overline{\mathrm{x}} \pm \mathrm{SD}\end{array}$ & $\begin{array}{l}\text { Without risk } \\
(\mathrm{N}=48) \\
\bar{x} \pm S D\end{array}$ & & \\
\hline Hemodialysis quality (Kt/V) & $1.59(0.28)$ & $1.57(0.26)$ & $1.61(0.3)$ & -0.58 & 0.566 \\
\hline Sodium (mmol/l) & $137(2.5)$ & $137.3(2.3)$ & $136.8(2.7)$ & 0.78 & 0.435 \\
\hline Potassium (mmol/l) & $4.84(0.83)$ & $4.84(1.07)$ & $4.84(0.64)$ & 0.02 & 0.984 \\
\hline Calcium (mmol/l) & $2.17(0.2)$ & $2.17(0.2)$ & $2.16(0.2)$ & 0.37 & 0.713 \\
\hline Phosphorus (mmol/l) & $1.68(0.51)$ & $1.72(0.48)$ & $1.65(0.53)$ & 0.54 & 0.590 \\
\hline
\end{tabular}

"t-test. 
Table 4. Predictors of High Scores in the Levine Questionnaire, Multivariate Regression (Hosmer-Lemeshow Goodness-of-Fit), Test (N=78)

\begin{tabular}{llll}
\hline Characteristic & Exp $(\mathrm{B})$ & $95 \% \mathrm{Cl}$ & $\mathrm{P}$ \\
\hline Age in 2016 (years) & 1.069 & $1.017-1.123$ & 0.008 \\
\hline Body mass index $\left(\mathrm{kg} / \mathrm{m}^{2}\right)$ & 1.157 & $1.031-1.3$ & 0.013 \\
\hline Predialytic urea $(\mathrm{mmol} / \mathrm{l})$ & 1.108 & $1.007-1.219$ & 0.035 \\
\hline
\end{tabular}

$\operatorname{Exp}(\mathrm{B})=$ Odds ratio; $\mathrm{Cl}=$ Confidence interval.

Table 5. Spearman's Correlation Coefficient (P) Between Levine Questionnaire Results and Characteristics of Participants with Carpal Tunnel Syndrome Related Symptoms ( $\mathrm{N}=30)$

\begin{tabular}{|c|c|c|c|c|c|c|}
\hline \multirow{3}{*}{ Characteristic } & \multirow{2}{*}{$\begin{array}{l}\text { Total } \\
\text { score }\end{array}$} & & \multicolumn{4}{|c|}{ Average score } \\
\hline & & \multicolumn{2}{|c|}{ Symptom severity } & \multicolumn{2}{|c|}{ Functional status } & \multirow[b]{2}{*}{$P$} \\
\hline & $\rho$ & $P$ & $\rho$ & $\mathrm{P}$ & $\rho$ & \\
\hline Age in 2016 (years) & -0.04 & 0.850 & -0.03 & 0.882 & 0.11 & 0.544 \\
\hline Body mass index $\left(\mathrm{kg} / \mathrm{m}^{2}\right)$ & 0.25 & 0.190 & 0.30 & 0.103 & 0.12 & 0.529 \\
\hline Time since starting hemodialysis* & 0.14 & 0.455 & 0.01 & 0.606 & 0.27 & 0.146 \\
\hline Age at start of hemodialysis (years) & -0.09 & 0.642 & -0.07 & 0.714 & 0.03 & 0.846 \\
\hline Hemodialysis quality (Kt/V) & 0.28 & 0.136 & 0.29 & 0.118 & 0.29 & 0.116 \\
\hline Creatinine $(\mu \mathrm{mol} / \mathrm{L})$ & -0.24 & 0.195 & -0.19 & 0.311 & -0.30 & 0.109 \\
\hline Urea (mmol/L) & -0.28 & 0.124 & -0.26 & 0.163 & -0.42 & 0.022 \\
\hline Hemoglobin $(g / L)$ & -0.17 & 0.363 & -0.13 & 0.463 & -0.22 & 0.253 \\
\hline Sodium (mmol/L) & 0.32 & 0.087 & 0.20 & 0.292 & 0.48 & 0.007 \\
\hline Potassium (mmol/L) & -0.05 & 0.785 & -0.06 & 0.754 & -0.12 & 0.529 \\
\hline Calcium (mmol/L) & 0.09 & 0.641 & 0.12 & 0.527 & 0.08 & 0.678 \\
\hline Phosphorus (mmol/L) & -0.22 & 0.224 & -0.20 & 0.286 & -0.31 & 0.093 \\
\hline
\end{tabular}

*Years.

Multivariate regression (Hosmer-Lemeshow goodness-of-fit) test showed that patient age, BMI and predialytic serum urea concentration were independent risk factors for development of carpal tunnel syndrome symptoms according to the screening Levine questionnaire $\left(\chi^{2}=16.75, \mathrm{P}=0.033\right)$. With each year of age, risk for development of carpal tunnel syndrome symptoms grew by $6.9 \%$, each $\mathrm{kg}$ of body mass increased that risk for $15.7 \%$, while raising the predialytic serum urea concentration raised that risk for $10.8 \%$ for each $\mathrm{mmol} / \mathrm{L}$ (Table 4 ).

We analyzed the correlations between participant characteristics in the group experiencing carpal tunnel syndrome symptoms with all three Levine questionnaire re- sults - total score, average symptom severity score and average functional status score (Table 5). Among participants experiencing carpal tunnel syndrome symptoms, average functional status score in the Levine questionnaire was higher, the higher the predialytic serum sodium concentration (Spearman correlation coefficient $\rho=0.48$, $\mathrm{P}=0.007$ ) and the lower the predialytic serum urea concentration (Spearman correlation coefficient $\rho=-0.42, \mathrm{P}=0.022$ ). There were no statistically significant differences between the total Levine questionnaire score and analyzed characteristics, as well as between average symptom severity score and analyzed characteristics. 


\section{Discussion}

Risk for carpal tunnel syndrome according to the screening Levine questionnaire was found in $38.5 \%$ of participants, which represents a considerable prevalence. Carpal tunnel syndrome in these patients differs from the one affecting the general population pathogenetically. That, in addition to the fact that carpal tunnel syndrome is the most common complication of hemodialysis-related amyloidosis $(5,24)$ is why it should be given special attention. Furthermore, many studies have shown that carpal tunnel syndrome prevalence is two times higher than its prevalence in the general population $(13,25,26)$.

One of the key risk factors for developing carpal tunnel syndrome in patients on chronic hemodialysis is duration of hemodialysis. A statistically significant link between duration of hemodialysis and risk for development of carpal tunnel syndrome was not found in this research, but the explanation for that finding can potentially be found in the duration of hemodialysis itself - it was relatively short, with the median duration of hemodialysis being 3 years and the interquartile range between 2 and 6 years. Harris and Brown stated that between $32 \%$ and $50 \%$ of patients on chronic hemodialysis for longer than 10 years are affected by carpal tunnel syndrome, while Otsubo et al. proved in their research that this prevalence jumps up to $80 \%$ in patients who have been on chronic hemodialysis for 30 years or even longer $(24,25)$.

Sixteen $(53.3 \%)$ of participants who experienced symptoms of carpal tunnel had unilateral symptoms, while $14(46.6 \%)$ of them had bilateral symptoms. The lower average functional status score suggests that participants in the group at risk, despite having symptoms related to carpal tunnel syndrome, did not experience a change in quality of life and an effect on performing daily activities. Among all participants, diabetic nephropahy was the most common underlying kidney disease. The fact that there were no statistically significant links between the risk for carpal tunnel syndrome and diabetic nephropathy suggests that the Levine questionnaire was specific enough not to mix and/or overlap with similar symptoms that participants might be experiencing due to diabetes.

Participants experiencing symptoms of carpal tunnel syndrome were older, $\mathrm{P}=0.044$, and had a higher BMI, $\mathrm{P}=0.019$. Furthermore, while it did not reach statistical significance, predialytic urea concentration was also higher in this group. This was an interesting finding, considering that there were no differences between the two groups in quality of hemodialysis, $\mathrm{P}=0.566$, which was determined using the $\mathrm{Kt} / \mathrm{V}$ formula, which, in turn, is based on predialytic and postdialytic serum urea concentration (19). Therefore, physiological aging processes, pathological effects of obesity and metabolic syndrome, as well as increased serum urea concetration all have a negative effect on patients on chronic hemodialysis and might contribute to the development of carpal tunnel syndrome as the most common complication of hemodialysis-related amyloidosis. Those results were somewhat expected because other studies have also shown that increased age (26) and a higher $\operatorname{BMI}(27,28)$ carry a higher risk for development of carpal tunnel syndrome. Using the multivariate regression analysis, we showed that the risk for development of carpal tunnel syndrome symptoms increases by $6.9 \%$ with each year of life, by $15.7 \%$ for every kilogram per square meter and by $10.8 \%$ for every $\mathrm{mmol} / \mathrm{L}$ of predialytic serum urea concentration increase. Using this method, we confirmed the independent influence of the aforementioned risk factors.

Participants in the group that was at risk for carpal tunnel syndrome started hemodialysis treatment earlier in life and have been on hemodialysis longer than participants who did not experience carpal tunnel 
syndrome related symptoms. This was another expected result because it reflects the development of clinical symptoms among patients on chronic hemodialysis - it takes a certain period of time for the amlyoid, $\mathrm{A} \beta 2-\mathrm{M}$ in this case, to be deposited in tissues (tissue surrounding the carpal tunnel in this case) in quantities that are large enough to cause manifestations (10).

When examining the differences in vascular access between the two groups of participants, the group at risk for carpal tunnel syndrome had a larger number of arteriovenous fistulas compared to the group without any symptoms of carpal tunnel syndrome. However, there were no statistically significant differences between the two groups based on the vascular access for hemodialysis and its positioning (left/right). Furthermore, there were no statistically significant links between the hand affected by carpal tunnel syndrome symptoms and the hand with the vascular access in the group, which was a useful piece of information because it eliminated the possibility that the cause of existing symptoms (pain, numbness, tingling etc.) screened for by the Levine questionnaire is not carpal tunnel syndrome, but complications of arteriovenous fistulas of catheters (e.g. arterial steal syndrome, venous hypertension) $(15,16)$.

The only statistically significant correlation found between demographic, anthropometric or laboratory data and test scores was between the average functional status score and predialytic serum urea concentration. This result was somewhat surprising because it showed that the average functional status score was higher, the lower the predialytic serum urea concentration. There is no simple explanation for this finding the expected correlation would have been opposite, with average functional status score rising with the elevation of predialytic serum urea concentration. It is possible that urea has a two-sided effect, or in other words, that it increases the risk up to a certain point and that in participants who are already symptomatic and at risk for carpal tunnel syndrome it perhaps reflects their nutritional state (29).

Further diagnostic evaluation is needed to confirm the diagnosis, which includes measuring the serum levels of $\beta 2$ microglobulin and, as a final confirmatory diagnostic method, electromioneurographic conduction study of the median nerve. Since carpal tunnel decompression, as therapy of choice for this disease, is not a complicated or extensive procedure, confirming the diagnosis of carpal tunnel syndrome caused by hemodialysis-associated amyloidosis would remove a source of pain and limitation in daily activities for many patients on chronic hemodialysis.

\section{Limitations of the Study}

Our study looked at the prevalence of carpal tunnel syndrome in chronic hemodialysis patients. However, due to the fact that the research was conducted in a single institution, the sample size was not large. Our hope is to expand the research to other institutions providing hemodialysis treatments to get a even more exact prevalence of carpal tunnel syndrome risk. Carpal tunnel syndrome can not be diagnosed based on a questionnaire alone, as was stated in the introduction, which limited our study due to not having information about symptoms or definitive diagnoses based on neurological examinations. Additionally, since this was a cross-sectional study, we could not get longitudinal results that would show questionnaire score progression over the course of a longer period.

\section{Conclusion}

Based on the results of our research, we can conclude that the prevalence of patients on 
chronic hemodialysis who are at risk for carpal tunnel syndrome is quite high (38.5\%) and that old age, high BMI and high predialytic serum urea concentration carry a higher risk for development of carpal tunnel syndrome symptoms. Furthermore, risk for carpal tunnel syndrome was more prevalent in participants who were on a regime of chronic hemodialysis longer and started hemodialysis earlier in life, while it is not affected by the underlying kidney disease. The presence of symptoms examined by the Levine questionnaire was not connected with the ipsilateral site of vascular access. Predialytic serum potassium concentration has a positive, while predialytic serum urea concentration has a negative correlation with the functional status of participants affected by symptoms examined by the questionnaire. Because of such high prevalence of at risk patients, further diagnostic evaluation is indicated to confirm the diagnosis of carpal tunnel syndrome and treat it with surgical decompression.

\section{What Is Already Known on this Topic}

Carpal tunnel syndrome is one of the most common complications of hemodialysis-related amyloidosis. Hemodialysis is an effective treatment option for end-stage kidney disease and with a large number of patients on a chronic regime, progressively worsening complications are common and should be addressed and treated.

\section{What this Study Adds}

This study sheds light on the prevalence of symptoms of carpal tunnel syndrome among chronic hemodialysis patients. With a third of patients showing symptoms, further diagnostic testing (laboratory measurement of $\beta 2$-microglobulin and electromioneurography) should be done to confirm the diagnosis and, if necessary, surgical resection performed to alleviate symptoms.

Acknowledgments: This research paper is based on the final graduation paper of the first author, which was presented at the Faculty of Medicine, Josip Juraj Strossmayer University of Osijek in June 2016.

Authors' Contributions: Conception and design: LZ; Acquistion, analysis and interpretation of data: MK and LZ; Drafting the article: MK; Revising it critically for important intellectual content: LZ; Approved final version of the manuscript: MK and LZ.
Conflicts of Interest: The authors declare that they have no conflicts of interest.

\section{References}

1. Jonjić N, Zamolo-Končar G, Kos M. Immune system disorders [in Croatian]. In: Damjanov I, Jukić S, Nola M, editors. Pathology. Zagreb: Medicinska naklada; 2011. p. 133-7.

2. Naiki H, Okoshi T, Ozawa D, Yamaguchi I, Hasegawa K. Molecular pathogenesis of human amyloidosis: Lessons from $\beta 2$-microglobulinrelated amyloidosis. Pathol Int. 2016;66(4):193201.

3. Marušić M, Grčević D. Major histocompatibility complex [in Croatian]. In: Taradi M, editor. Immunology. Zagreb: Medicinska naklada; 2010. p. 100-2.

4. Yamamoto S, Kazama JJ, Maruyama H, Narita I. Hemodialysis-related amyloidosis: Pathogenesis and clinical features in patients undergoing hemodialysis treatment. In: Feng D, editor. Amyloidosis. InTechOpen, 2013. [cited 2016 Apr 20]. Available from: http://www.intechopen.com/books/ amyloidosis/hemodialysis-related-amyloidosispathogenesis-and-clinical-features-in-patientsundergoing-hemodialysis-trea.

5. Orlando RA, Rader K, Authier F, Yamazaki H, Posner BI, Bergeron JJM, et al. Megalin is an endocytic receptor for insulin. J Am Soc Nephrol. 1998;9(10):1759-66.

6. Kay J, Henrich WL, Qunibi WY, Berns JS, Schwab SJ, Sheridan AM. Hemodialysis-related amyloidosis. In: Post TW, Berns JS, Schwab SJ, Sheridan AM, editors. Waltham, MA: UptoDate; 2015. [cited 2016 Apr 21]. Available from: http://www. uptodate.com/contents/hemodialysis-related-amyloidosis.

7. Porter MY, Routledge KE, Radford SE, Hewitt EW. Characterization of the response of primary cells relevant to hemodialysis-related amyloidosis to $\beta 2$-microglobulin monomer and fibrils. PloS ONE. 2011;6(11):e27353.

8. Kiss E, Keusch G, Zanetti M, Jung T, Schwarz $A$, Schocke $M$, et al. Hemodialysis-related amyloidosis revisited. AJR Am J Roentgenol. 2005;185(6):1460-7.

9. Jadoul M, Drüeke TB. $\beta 2$ microglobulin amyloidosis: an update 30 years later. Nephrol Dial Transplant. 2016;31(4):507-9.

10. Schiffl H. Impact of advanced hemodialysis technology on the prevalence of hemodialysis-related amyloidosis in long-term maintenance hemodialysis patients. Hemodial Int. 2014;18(1):136-41. 
11. Pećina M. Canalicular syndromes [in Croatian]. In: Pavičić A, editor. Orthopedics. Zagreb: Naklada Ljevak; 2004. p. 411-13.

12. Ibrahim I, Khan W, Goddard N, Smitham P. Carpal tunnel syndrome: A review of the recent literature. Open Orthop J. 2012;6(Suppl1):69-76.

13. Kang HJ, Koh IH, Lee WY, Choi YR, Hahn SB. Does carpal tunnel release provide long-term relief in patients with hemodialysis-associated carpal tunnel syndrome? Clin Orthop Relat Res. 2012;470(9):2561-5.

14. Leon C, Asif A. Arteriovenous access and hand pain: the distal hypoperfusion ischemic syndrome. Clin J Am Soc Nephrol. 2007;2(1):175-83.

15. Bracale UM, Crescenzi C, Narese D, Giribono AM, Viviani E, Ferrara D, et al. Management of finger gangrene caused by steal syndrome in vascular access for hemodialysis. Personal experience and a brief review of the literature. Ann Ital Chir. 2015;86(3):239-45.

16. Kocyigit I, Unal A, Guney A, Mavili E, Deniz K, Kocyigit $M$ et al. Carpal tunnel release surgery and venous hypertension in early hemodialysis patients without amyloid deposits. ScientificWorld Journal. 2013;2013:481348.

17. Levine DW, Simmons BP, Koris MJ, Daltroy LH. Hohl GG, Fossel AH, et al. A self-administered questionnaire for the assessment of severity of symptoms and functional status in carpal tunnel syndrome. J Bone Joint Surg Am. 1993;75(11):1585-92.

18. Meirelles LM, dos Santos JBG, dos Santos LL, Branco MA, Faloppa F, Leite VM, et al. Evaluation of Boston questionnaire applied at late post-operative period of carpal tunnel syndrome operated with the paine retinaculatome through palmar port. Acta Ortop Bras. 2006;14(3):126-32.

19. Kovačić V. Kt/V as a measure of total hemodialysis [in Croatian]. Liječ Vjesn. 2003;125:188-91.

20. Daugirdas JT, Leypoldt JK, Akonur A, Greene T, Depner TA. Improved equation for estimating single-pool Kt/V at higher hemodialysis frequencies. Nephrol Dial Transplant. 2013;28(8):215660.
21. Theofilou P, Togas C, Vasilopoulou C, Minos C, Zyga S, Tzitzikos G. The impact of Kt/V ureabased hemodialysis adequacy on quality of life and adherence in haemohemodialysis patients: a cross-sectional study in Greece. Health Psychol Res. 2015;3(1):1060.

22. Maduell F, Garcia-Valdecasas J, Garcia H, Hernandez-Jaras J, Siguenza F, del Pozo C, et al. Validation of different methods to calculate $\mathrm{Kt} / \mathrm{V}$ considering posthemodialysis rebound. Nephrol Dial Transplant. 1997;12(9):1928-33.

23. Ivanković D, Božikov J, Kern J, Kopjar B, Luković G, Vuletić S, et al. Basics of statistical analysis for medical students [in Croatian]. Zagreb: Medicinski fakultet Sveučilišta u Zagrebu; 1988.

24. Otsubo S, Kimata N, Okutsu I, Oshikawa K, Ueda $\mathrm{S}$, Sugimoto $\mathrm{H}$, et al. Characteristics of hemodialysis-related amyloidosis in patients on haemohemodialysis therapy for more than 30 years. Nephrol Dial Transplant. 2009;24(5):1593-8.

25. Harris SA, Brown EA. Patients surviving more than 10 years on haemohemodialysis. The natural history of the complications of treament. Nephrol Dial Transplant. 1998;13(5):1226-33.

26. Kopec J, Gadek A, Drozdz M, Miskowiec K, Dutka J, Sydor A, et al. Carpal tunnel syndrome in hemodialysis patients as a hemodialysis-related amyloidosis manifestation--incidence, risk factors and results of surgical treatment. Med Sci Monit. 2011;17(9):CR505-9.

27. Hoshino J, Yamagata K, Nishi S, Nakai S, Masakane I, Iseki K, et al. Carpal tunnel surgery as proxy for hemodialysis-related amyloidosis: results from the Japanese society for hemodialysis therapy. Am J Nephrol. 2014;39(5):449-58.

28. Werner RA, Albers JW, Franzblau A, Armstrong TJ. The relationship between body mass index and the diagnosis of carpal tunnel syndrome. Muscle Nerve. 1994;17(6):632-6.

29. Schoenfeld PY, Henry RR, Laird NM, Roxe DM. Assessment of nutritional status of the National Cooperative Hemodialysis Study population. Kidney Int Suppl. 1983;(13):S80-8. 